\title{
NOTES ON MEASURES IN INFANT FEEDING.
}

\author{
BY
}

G. A. HARRISON, B.A., M.D.,

Biochemist, The Hospital for Sick Children, Great Ormond Street. WITH

HUGH THURSFIELD, D.M., F.R.C.P.

The following notes are written in the hope of once more drawing attention to the danger of using a teaspoon for measuring dried milks.

Some physicians prescribe so many "level teaspoonsful," others so many ". heaped teaspoonsful " of dried milk.

Table 1 shows the actual weights of one particular milk as measured out by a series of nurses. The same spoon and the same dried milk were used throughout.

TABLE 1.

\begin{tabular}{|c|c|c|c|}
\hline \multicolumn{2}{|c|}{$\begin{array}{l}\text { Measured by } \\
\text { Nurse No. }\end{array}$} & $\begin{array}{l}\text { Weight in gm. of } \\
1 \text { "level" teaspoonful. }\end{array}$ & $\begin{array}{c}\text { Weight in gm. of } \\
1 \text { "heaped" teaspoonful. }\end{array}$ \\
\hline & 1 & $1 \cdot 7$ & $2 \cdot 9$ \\
\hline & 2 & $1 \cdot 5$ & $2 \cdot 5$ \\
\hline & 3 & $2 \cdot 1$ & $3 \cdot 8$ \\
\hline & 4 & $2 \cdot 0$ & $4 \cdot 9$ \\
\hline & 5 & $2 \cdot 7$ & $5 \cdot 0$ \\
\hline & 6 & $2 \cdot 5$ & $3 \cdot 5$ \\
\hline & 7 & - & $2 \cdot 5$ \\
\hline Highest & $\ldots$ & $2 \cdot 7$ & $5 \cdot 0$ \\
\hline Lowest & $\cdots$ & $1 \cdot 5$ & $2 \cdot 5$ \\
\hline Mean & $\cdots$ & $2 \cdot 1$ & $3 \cdot 6$ \\
\hline
\end{tabular}

It is easy to understand why nurse No. 5 should acquire a reputation for making her babies gain weight, if, say, she took over the duties of nurse No. 2.

That variations do occur owing to the different sizes of different teaspoons is, of course, well recognised, and needs only to be mentioned. In practice one particular spoon is usually put aside for the purpose of measuring the food, or, as in institutional work, it may often happen that all the teaspoons are of the same pattern. 


\section{ARCHIVES OF DISEASE IN CHILDHOOD}

That one milk powder is lighter than another is frequently obvious to the naked eye, but we feel that the extent of the variations due to the differeni densities of different foods is not properly appreciated. In Table 2 are inclucled a number of the foods commonly used in infant feeding.

\section{TABLE 2.}

Showing the variations due to the different densities of different foods. All the measurements were made by the same person with the same teasponn or tablespoon.

\begin{tabular}{|c|c|c|}
\hline $\begin{array}{l}\text { Substance } \\
\text { weighed. }\end{array}$ & $\begin{array}{l}\text { Weight in gm. of } \\
1 \text { level teaspoonful. }\end{array}$ & $\begin{array}{l}\text { Weight in gm. of } \\
1 \text { level tablespoonful. }\end{array}$ \\
\hline A & $1 \cdot 0$ & $5 \cdot 8$ \\
\hline B & 1.5 & $7 \cdot 0$ \\
\hline $\mathrm{C}$ & $1 \cdot 5$ & $7 \cdot 4$ \\
\hline $\mathrm{D}$ & $1 \cdot 9$ & $8 \cdot 6$ \\
\hline$E$ & 1.9 & $9 \cdot 0$ \\
\hline $\mathrm{F}$ & $2 \cdot 0$ & 8.5 \\
\hline $\mathrm{G}$ & $2 \cdot 0$ & $9 \cdot 1$ \\
\hline $\mathrm{H}$ & $2 \cdot 0$ & $8 \cdot 3$ \\
\hline I & $2 \cdot 3$ & $10 \cdot 0$ \\
\hline $\mathrm{J}$ & $2 \cdot 4$ & $12 \cdot 5$ \\
\hline $\mathrm{K}$ & $2 \cdot 9$ & $14 \cdot 5$ \\
\hline $\mathrm{L}$ & $3 \cdot 0$ & $14 \cdot 3$ \\
\hline Casein & $2 \cdot 3$ & 10.0 \\
\hline Dextri-maltose & $2 \cdot 9$ & $14 \cdot 8$ \\
\hline $\begin{array}{l}\text { Cane-sugar } \\
\text { (granulated) }\end{array}$ & $4 \cdot 3$ & $21 \cdot 9$ \\
\hline
\end{tabular}

The difference in density alone might easily account for an improvement on changing the diet from one food to another.

The practical importance of these facts may be illustrated by the following examples. A certain well-known dried milk (which we will call 1)) has the following composition :-

$$
\begin{array}{lccc} 
& \text { Carbohydrate. } & \text { Protein. } & \text { Fat. } \\
100 \mathrm{gm} \text {. of the dry milk powder contain } & 41 \cdot 0 & 22 \cdot 2 & 27 \cdot 4
\end{array}
$$

\begin{tabular}{ccc}
\multicolumn{3}{c}{ Grammes of } \\
Carbohydrate. & Protein. & Fat. \\
$41 \cdot 0$ & $22 \cdot 2$ & $27 \cdot 4$
\end{tabular}

On reconstituting milk from this powder by the addition of water, according to the instructions on the tin, it is generally believed that the resulting mixture will have approximately the same composition as cow's milk. From the instructions it is learnt that the mixture is to be made in the proportion of 1 teaspoonful of powder to 2 tablespoonsful of water. Let us assume for the moment that the powder measured in 1 teaspoon weighs 1 drachm or $3.55 \mathrm{gm}$. and that the volume of 2 tablespoonsful of water is 1 ounce or $28.4 \mathrm{cc}$. In other words let us suppose that we are prescribing "one drachm to the ounce." One drachm to one ounce, or $3.55 \mathrm{gm}$. to $28.4 \mathrm{cc}$. is the same as $12.5 \mathrm{gm}$. to $100 \mathrm{cc}$. Knowing the composition of $100 \mathrm{gm}$. of milk powder D it is easy to calculate the composition of $12.5 \mathrm{gm}$. 


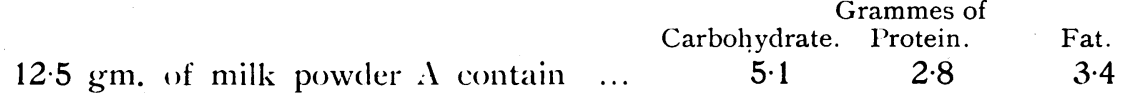

And of course our mixture of $12.5 \mathrm{gm}$. powder $\mathrm{D}$ and $100 \mathrm{cc}$. water will contain the same. The composition of cow's milk varies, but the following is a fair average :-

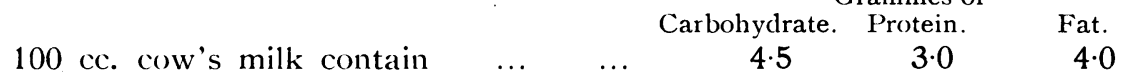

It will be seen therefore that the belief that reconstituted milk has approximately the same composition as fresh cow's milk is correct, on the above assumption-but what an assumption it is! One level teaspoonful of powder $D$ according to our meastirements, weighs only $1.9 \mathrm{gm}$ ! Let us suppose that the ounce of water is measured out in a measure (and this is a common practice) and correctly. Then $1.9 \mathrm{gm}$. to $28.4 \mathrm{cc}$. is the same as $6.7 \mathrm{gm}$. to $100 \mathrm{cc}$., and

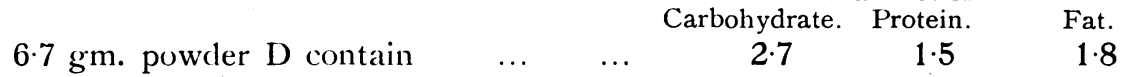

The concentration of this mixture is approximately half that which both manufacturer and physician imagine the infant is receiving

In order to give the reader an opportunity of checking our findings in Table 2 we would mention that the teaspoon we used held $4 \frac{1}{2} \mathrm{cc}$. of water and

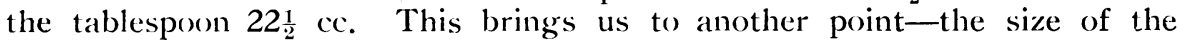
tablespoon. The tablespoon employed was the stanclard pattern commonly used in the wards at the Hospital for Sick Children and did not strike us as unusually large. It was rather astonishing to find that its cubic capacity was nearer one ounce than half an ounce.

There is one other point. It is not unknown for a physician to claim that his infant patient has so many calories per diem, knowing that his nurse measures the dried milk he orders with a teaspoon. Suppose he prescribes milk powder D, seven feeds in the 24 hours, and each feed ziii ad $\mathfrak{z}_{\text {iii. He }}$ makes his calculation of the intake of calories on the basis that $3^{i}$ corresponds to $3.55 \mathrm{gm}$. of milk powder $\mathrm{D}$ :-

$$
21 \times 3.55=74.55 \mathrm{gm} \text {. in } 24 \text { hours. }
$$

$100 \mathrm{gm}$. contain $41.0 \mathrm{gm}$. carbohydrate, $22.2 \mathrm{gm}$. protein, and $27.4 \mathrm{gm}$. fat, which yields 514 calories $([41 \cdot 0+22 \cdot 2] \times 4 \cdot 1$ plus $27 \cdot 4 \times 9 \cdot 3)$. Therefore $74.55 \mathrm{gm}$. milk powder D yield 383 calories.

He calculates that his patient is receiving 383 calories in the 24 hours. According to our measurements, however, the patient only receives $21 \times 1.9$ or $39.9 \mathrm{gm}$. of milk powder D which yields 205 calories, or just over half what he is supposed to be having.

The remedy for all this is, of course, obvious. If the physician really wishes to know how much is being given to his patient, or if he wishes to calculate the caloric intake, he must have the dried milk weighed. We do not wish, of course, to suggest that it is necessary for every infant to have every particle of food weighed. Children were fed before balances were invented. Mothers and doctors have learnt from experience the quantities required, whether they employ teaspoons as a rough measure, or whether they judge the amount by eye. But real knowledge can only be acquired on the basis of accurate quantitative data, and teaspoonsful do not make for accuracy. 
There is just one other practical point. It would be convenient if the manufacturer's directions did lead to a reconstitution of milk of approximately the same composition as cow's milk or human milk. We have shown that the present method does not do so. Setting aside the use of the balance which is not practical politics for the majority, can anything else be done? Some firms supply a special measure with each tin of infants' Iried food. These measures are open to the same objections as the teaspoon (Table 3) with this difference-that the measure could easily be made of such a size as to contain on the average $3.55 \mathrm{gm}$. of the particular dried food. This would in the long run be an improvement on the teaspoon.

\section{TABLE 3.}

Showing the variations using the measure supplied by the trade with the tin of infants' dried food $\mathrm{K}$.

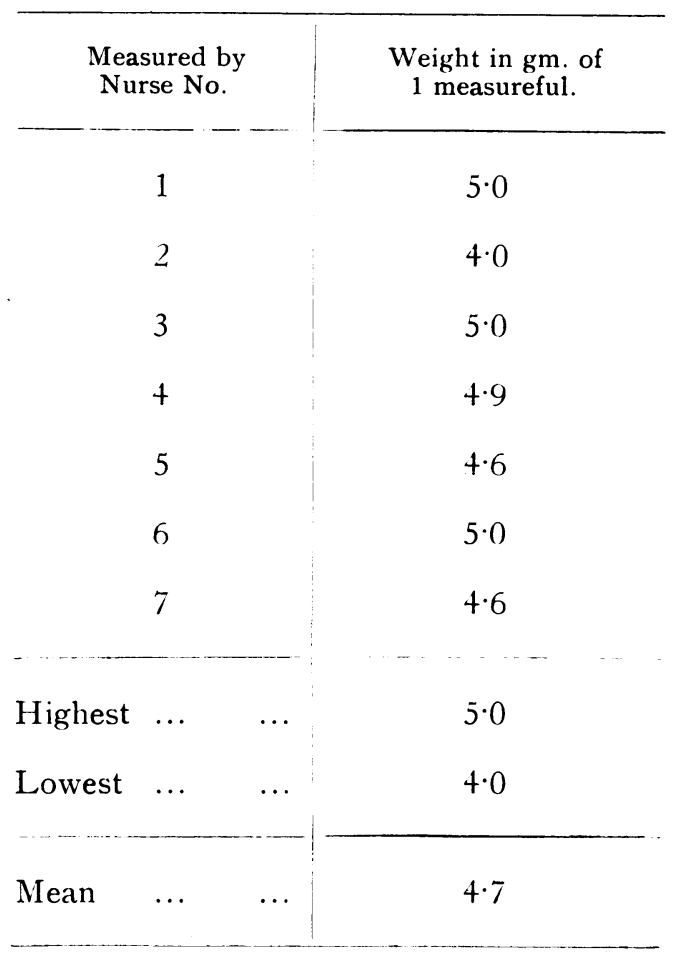

Table 3 shows the results of our experiments using one such measure supplied with dried food $K$. It will be seen that in our hands this measure was too large (mean measureful $4.7 \mathrm{gm}$.), but it will be noted that the variations between the results given by different nurses was much smaller than in the case of the teaspoon. The firm supplying this measure, to our mind, quite spoiled a step in the right direction by giving instructions on the label of the tin to use so many measurefuls or teaspoonsful, thus suggesting, perhaps unintentionally, that the measure and a teaspoon were of the same capacity! Our teaspoonful of this particular food weighed $2.9 \mathrm{gm}$. $A s^{\prime}$ an alternative for the manufacturer we would suggest that he might do 
what we have done, viz., determine the weight of his food contained in an acerage level teaspoonful. It would be helpful if he would state what was the capacity of the teaspoon he regarded as of average size, in the same way that we have stated that our teaspoon held $4 \frac{1}{2} \mathrm{cc}$. of water; or better still, perhaps the manufacturers would consider jointly the possibility of adopting and supplying some standard measure. Having fixed the measure it would only be necessary to alter the instructions on the tin so that when $\mathrm{X}$ measurefuls were added to $\mathrm{Y}$ ounces of water the resulting reconstituted milk approximated in composition to that of cow's milk, or of human milk whichever be taken as standard. It would be a matter of relatively simple experiment to determine $\mathrm{X}$ and $\mathrm{Y}$, and to arrange that they were convenient whole numbers. 